\title{
An in-situ experimental testing method of swelling pressure on expansive soils
}

\author{
Chen Ronglin, Zeng Zhixing \\ College of Civil Engineering, Huaqiao University, 361021, China
}

\begin{abstract}
Keywords: Expansive Soils; Swelling Pressure; In-situ Experimental Test
\end{abstract}
\begin{abstract}
Expansive soil has been the engineering application difficulties due to its water swelling, softening and dehydration shrinkage, cracking and other characteristics, China is one of the countries with the most extensive expansive soil distribution. In the construction of civil engineering such as railway, highway, water conservancy and construction, the problem of expansive soil is always difficult to solve. At present, many studies have been made on the indoor research of expansive soils, but there are few field experiments on the strength, deformation and mechanical properties of expansive soils. As a result, it is very necessary to measure the swelling pressure of expansive soils, because the laboratory results cannot usually reflect practical situations. Based on "loading-swelling method" and the results of loaded swelling rate tests, the swelling pressure values are obtained through linear interpolation. Finally, the field test results show that the swelling pressure can reflect the real situations, to demonstrate that the testing method can be applied in many areas.
\end{abstract}

\section{Introduction}

Expansive soils are extremely sensitive to environmental changes such as temperature, humidity, pressure and groundwater [1]. Once exposed, they are prone to water swelling, weathered dry cracking and unloading cracking, showing poor engineering properties. Expansion of the expansion and contraction of expansive soils accelerate the deformation of the surrounding soils and prolongs the deformation continuation time so that underground caverns generally have the characteristics of cracking, Swelling and other deformation phenomena, and remediation difficulties [2]. The embankment built in the expansive soil area will have the effect of wetting and drying of the expansive soil. The dry soil will lose water and shrinkage and the micro-cracks will open in the dry season, providing a channel for infiltration of surface water. The wetting soil will absorb water and swell, reducing the strength, sinking out of line, deformation of the line to take the shape, shoulder bulge, ditch damage, mud spill Road and other diseases. Due to the infiltration of surface water, the strength of foundation bearing capacity will be reduced and the design requirements will not be met. Expansion pressure will easily cause uneven settlement of buildings. When expansive soil is used as bearing layer of deep foundation such as piles of buildings, the bearing capacity of piles will cause problems due to the influence of water during the construction of piles [3].

Due to the characteristics of expansive soil such as water swelling and water shrinkage, various types of engineering construction in expansive soil areas are often destroyed, resulting in huge economic losses [4]. The Bou-Roumi water conservancy tunnel in Algeria, the Alpine railway tunnel in Italy to Austria and Zhongshan Tunnel $\mathrm{J}$ in Japan all found that a large amount of expansive soil and expansible soft surrounding rock 171 were found, resulting in a substantial increase in construction cost [5]. In countries such as Sudan, Norway and Germany, expansive soil covers more than one third of the country's total land area. Buildings and structures in expansive soil areas, farmland irrigation systems, various pipelines, road and rail systems, and other structures Often due to swelling of expansive soil water swelling and shrinkage caused by water loss [61. According to statistics, in the United States each year due to the issue of expansive soil damage to housing construction, road traffic and underground pipe network, the economic losses caused by more than 2.3 billion

The problem of expansive soils was first recognized by soil mechanics engineers in the late 1930s when the Bureau of Reclamation recognized the problem of expansive soils for the first time 
in a steel siphon foundation project in Ovchio, Oregon [7]. As a result, Development, the study of expansive soil caused more and more attention of geotechnical engineering. In the 1950s, when the Chengdu-Chongqing Railway was constructed, our country first encountered the harm caused by the expanded clay in Chengdu, which opened the prelude to the study of the expansive soil in China [8]. In the mid-1970s, China conducted a large-scale census of the expansive soil work, set up a number of test bases, carried out fruitful scientific research and made a lot of scientific research. The study on the microscopic mechanism of expansive soils includes the study of the mineral composition of expansive soils and the structural characteristics of expansive soils, both of which are also one of the most important features of expansive soils [9]. The mineral composition of expansive soils should be firstly identified by its mineral composition at present, the main identification methods are X-ray diffraction (XRD), differential scanning calorimetry (TDA) scanning electron microscopy (SEM) and infrared spectroscopy. The chemical constituents are mainly studied by the methods of total chemistry and trace element analysis of two means [10].

\section{In-situ experimental testing method of swelling pressure}

\subsection{Test Principal}

Expansive force is an important indicator of expansive soil swelling characteristics, according to the basic terminology of geotechnical engineering (GB / T50279.98) as defined in the expansion of soil is not allowed to fully absorb lateral deformation, so that it does not occur. Expansive soil expansive force includes vertical expansive force and horizontal expansive force. This paper focuses on the relevant characteristics of vertical expansive force. At present, the test methods for the expansion force mainly focus on the indoor test methods, mainly including the expansion back pressure method, the load expansion method and the load balancing method.

Expansion of the back pressure method: the method is full of water saturated soil conditions, the soil free expansion to achieve maximum stability, and then pressure to restore soil to the original volume. In fact, the pressure on the soil Jing is a consolidation process, the soil skeleton particles crushing, slipping, reorganization; to reduce the pores, free pore water discharge. However, a large number of studies have shown that swelling is the physicochemical to mechanistic process of grainwater-film thickening between wedges and grains. This shows that the force measured by this method cannot be considered as the expansion pressure.

There is a charge expansion method, which uses a series of different load values and the relationship between the amount of expansion to make a load expansion curve to determine the maximum expansion force of the soil, using a single sample and multiple samples. Laboratory commonly used load expansion test is based on this principle to calculate the maximum expansion of soil. However, when the method is applied with a large load, it is easy to make the soil produce compressive deformation, resulting in the change of the dry density and structure of the soil, which makes the test value different from the real value.

Load balance method, the principle of this method is to continuously exert load in the process of soil water absorption and expansion, so as to keep the volume of soil constant. After the test, the accumulated value of test load is the maximum expansion force of soil. The test process basically does not destroy the soil structure, in line with the physical meaning of expansive force, is widely used in laboratory tests, the standard is given in the expansion force test is based on the principle. This method requires that each time the test load value is correct and the loading operation requires fine, cannot produce impact force, the test requires higher.

Obviously, the actual conditions of on-site rock and soil are very different from the indoor test conditions. The test results of indoor expansion force test often cannot really reflect the real situation of the soil in the field. Therefore, the expansive soil expansive force in situ testing is particularly important. This test is in full accordance with the definition of expansive force in "Geotechnical Basic Terminology Standard". During the test, the vertical expansion and deformation of the soil body is completely restricted by the reaction force system, and the relevant instruments are used to test the embedded in soil Earth pressure box readings to represent the 
vertical expansion force generated by soil. The method truly reflects the generation and development process of vertical expansive force of soils on the site, and obtains the vertical expansive force and vertical expansive force time-history characteristics of the soil. Construction has important guiding significance.

\subsection{Test Introduction}

The number of tests. Medium-strong expansive soil test section, two sets of parallel mediumstrong expansive soil vertical expansive force in situ test in two adjacent sites (denoted as No. 1 and No. 2 respectively); In the expansive soil test section, two sets of parallel weak-medium expansive soil vertical expansive force in-situ tests were carried out on two adjacent sites (denoted as No.3 and No.4, respectively).

Test process. Medium-strong expansive soil vertical expansive force in situ test: November 11, 2016 to November 18, which lasted 8 days to complete the site 1 vertical expansion force in situ test; November 27, November to November 2016 On the 29th, which lasted 3 days, the site 2 vertical expansion force in situ test. Weak-medium expansive soil vertical expansion force in situ test: December 31, 2016 to January 4, 2016, which lasted 5 days to complete the site 3 vertical expansion force in situ test; January 7, 2016 to January 11, 2016, which lasted 5 days to complete the site 4 vertical expansion force in situ test.

\subsection{Test point soil characteristics}

In-situ test of vertical expansive expansive soil is selected. Strong expansive soil test section DK200 +510 near, weak - medium expansive soil vertical expansion force in situ test selected weak. In the expansive soil test section DKl68 +580 near the two test sites are shallow hill topography, soil characteristics and physical and mechanical indicators provided by the Second Hospital of China Railway show that the selected test point has a typical representative.

Medium - strong expansive soil test point. In the mid-0 strong expansive soil test point, it is found that the soil is expansive soil, with the remnant of Triassic mudstone and reticular clay soil of Youjiang terraces. The soil is brownish red, brownish yellow and hard to Hard plastic, ferrous manganese nodules, local enrichment into layers, and micro-breccia breccias, with moderate to strong expansibility, distributed in the mound gentle slope surface within the scope of soil thickness $0 \sim 6 \mathrm{~m}$.

Physical and mechanical indicators: natural density $\mathrm{p}=1.969 / \mathrm{cm} 3$, natural moisture coo $=$ $23.35 \%$, natural porosity e $=0.74$, liquid limit cot $=44.40 \%$, plasticity index $\mathrm{I}=22.18$, the natural fast shear cohesion $\mathrm{C}=36.40 \mathrm{kPa}$, the internal friction angle $\mathrm{O}=13.70$, the free expansion rate $\mathrm{F}=$ $45 \% \sim 76 \%$, the residual shear internal friction angle 7.17, residual shear strength coefficient Sa $0.31 \sim 0.57$.

Physical and mechanical indicators: natural density $\mathrm{p}=1.909 / \mathrm{cm} 3$, natural water content eoo $=$ $15.9 \%$, natural void ratio e $=0.62$, liquid limit $=33.2 \%$, plastic index $\mathrm{I}$, free expansion rate $\mathrm{F}=24 \%$ $\sim 55 \%$.

\subsection{Test site preparation}

In the expansive soil test points, two $3 \mathrm{~m} \times 6 \mathrm{~m}$ rectangular test sites shall be excavated, which shall be recorded as No. 1 4 test site respectively, of which No. 1 and No. 2, No. 3 and No. 4 are 20 meters away from the test site. The level of the test site is to be determined by level: near elevation DK200 + 510, the elevation of the test site is $131.00 \mathrm{~m}$ (the digging depth is about 2.5 blood) and the brown expansive soil shows, which is shown in Fig.1-1; Near the DK168 +580 test site, the elevation of $144.00 \mathrm{~m}$ is determined (excavation depth of about ZOOm) and the reddish brown expansive soil shows, which is shown in Fig.1. 

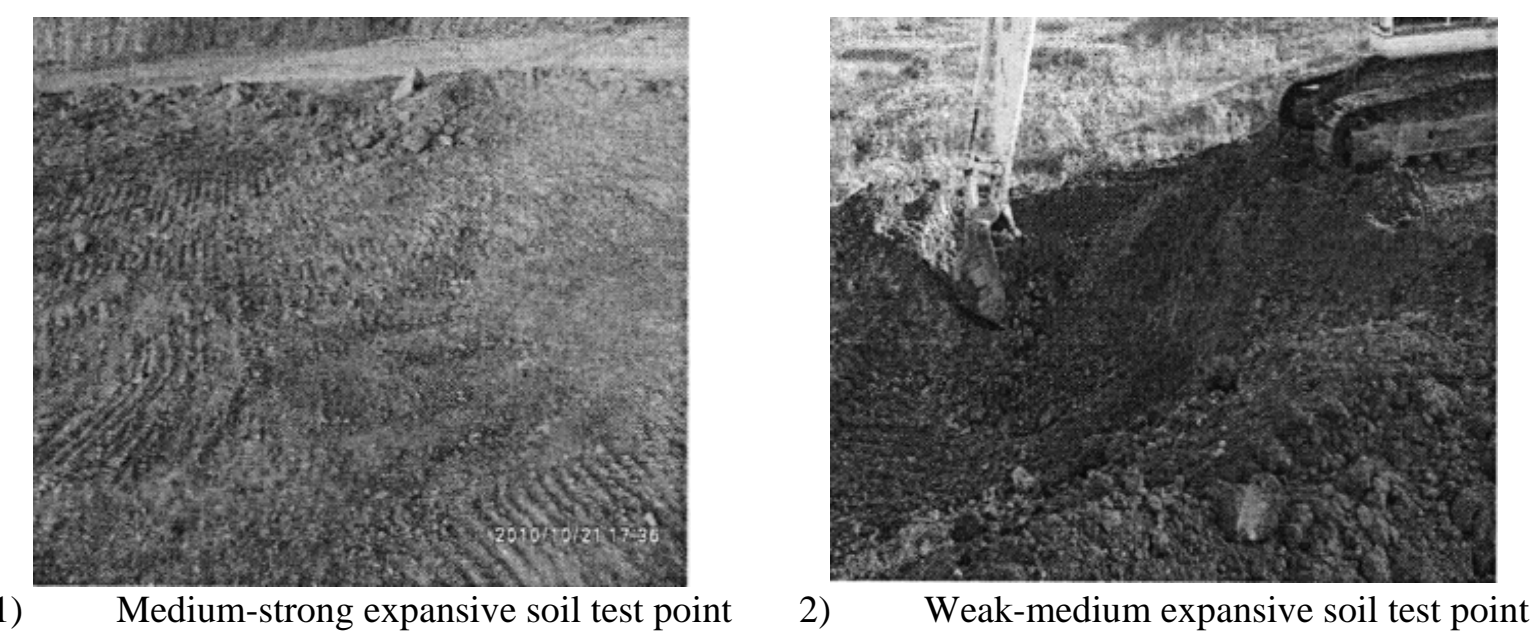

Fig.1 Two types of soil test point

\section{Medium-strong in-situ test of expansive soil vertical expansive force}

\subsection{The limit of medium-strong expansive soil vertical expansive force}

In this test, the vertical expansion force of soil after water immersion is indicated by testing the readings of earth pressure cells buried in the surface soil. The final earth pressure box reading obtained from the test is the vertical limit expansive force of the soil, as shown in the following

Tab.1 Medium-strong expansive soil vertical expansive force limit

\begin{tabular}{cccccc}
\hline \hline $\begin{array}{c}\text { Site } \\
\text { Number }\end{array}$ & $\begin{array}{c}\text { Soil pressure box } \\
\text { No.1 }(\mathrm{kPa})\end{array}$ & $\begin{array}{c}\text { Soil pressure box } \\
\text { No.2 }(\mathrm{kPa})\end{array}$ & $\begin{array}{c}\text { Soil pressure box } \\
\text { No.3 }(\mathrm{kPa})\end{array}$ & $\begin{array}{c}\text { Soil pressure box } \\
\text { No.4 }(\mathrm{kPa})\end{array}$ & $\begin{array}{c}\text { Mean Value } \\
(\mathrm{kPa})\end{array}$ \\
\hline 1 & 338 & 311 & 100 & 155 & 238 \\
2 & 135 & 210 & 166 & 169 & 170 \\
\hline \hline
\end{tabular}

As can be seen from the above table, the maximum vertical expansion limit of site No. 1 is 338 $\mathrm{kPa}$, the minimum is $100 \mathrm{kPa}$, the average is $226 \mathrm{kPa}$; the maximum vertical expansion limit of site No. 2 is $210 \mathrm{kPa}$ and the minimum is $135 \mathrm{kPa}, 170 \mathrm{kPa}$.

It can be seen from Figure 2 that the expansion rate has a good linear relationship with the vertical expansion force. Suppose the vertical expansion force is represented by $Y$ and the expansion rate is represented by $\mathrm{x}$. The relationship between vertical expansion force and expansion rate can be expressed as The linear equation $\mathrm{Y}=\mathrm{ax}+\mathrm{b}$, here take a 2257.5, $\mathrm{b}=199.3$, the correlation coefficient $\mathrm{R} 2=0.982$. When the soil expansion rate is zero, that is, $\mathrm{x}$ takes zero value, then the vertical expansion force is $199 \mathrm{kPa}$. According to the definition of vertical expansion force, the value is the vertical limit expansion test force.

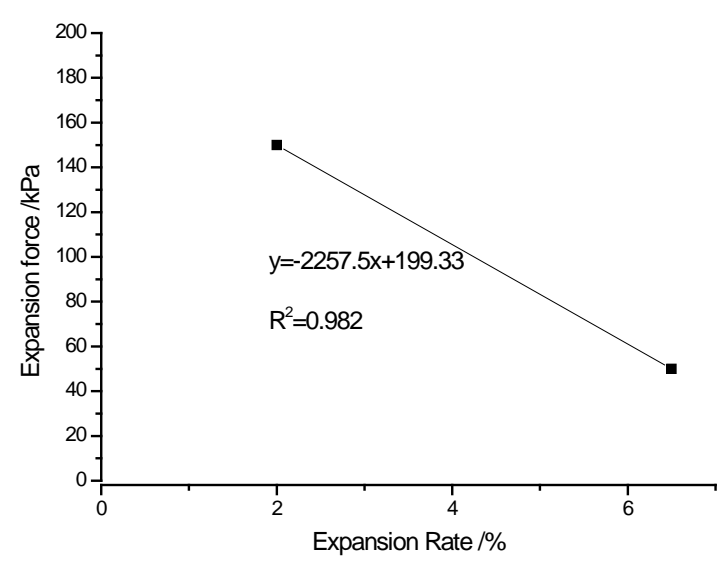

Fig.2 The relationship between vertical expansion force and expansion rate 
The results show that the vertical limit expansive force obtained by the test of vertical expansive force in the field is close to that of the indoor test, both of which are about $200 \mathrm{kPa}$. However, there is a certain discrepancy in the field test results. The vertical limit expansive force values obtained by the two tests differ greatly. Among them, the vertical limit expansive force on site No. 1 is 226 $\mathrm{kPa}$, that on No. 2 site is $170 \mathrm{kPa}$, the difference between the two is more than $50 \mathrm{kPa}$. Even in the same group of tests, the values of the four earth pressure boxes are quite different. Taking the site No.1 as an example, the difference between the maximum value and the minimum value is more than $200 \mathrm{kPa}$.

\section{Weak-medium in-situ test of expansive soil vertical expansive force}

Similar to medium-strong expansive soil area, weak. In the expansive soil area, two sets of parallel tests are also conducted on typical sites. The test sites are recorded as Site 3 and Site 4 respectively. The vertical limit expansive forces of the two test sites are shown in Table 2.

Tab.2 Medium-strong expansive soil vertical expansive force limit

\begin{tabular}{cccccc}
\hline \hline $\begin{array}{c}\text { Site } \\
\text { Number }\end{array}$ & $\begin{array}{c}\text { Soil pressure box } \\
\text { No.1 }(\mathrm{kPa})\end{array}$ & $\begin{array}{c}\text { Soil pressure box } \\
\text { No.2 }(\mathrm{kPa})\end{array}$ & $\begin{array}{c}\text { Soil pressure box } \\
\text { No.3 }(\mathrm{kPa})\end{array}$ & $\begin{array}{c}\text { Soil pressure box } \\
\text { No.4 }(\mathrm{kPa})\end{array}$ & $\begin{array}{c}\text { Mean Value } \\
(\mathrm{kPa})\end{array}$ \\
\hline 1 & 208 & 109 & 149 & 160 & 156.5 \\
2 & 160 & 266 & 147 & 64 & 159 \\
\hline \hline
\end{tabular}

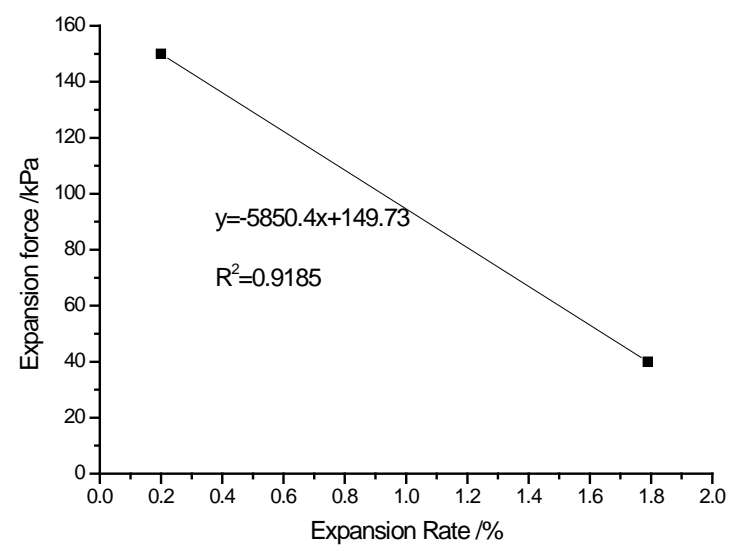

Fig.3 The relationship between vertical expansion force and expansion rate

As can be seen from the above table, the maximum vertical expansion force of site No.3 is $208 \mathrm{kPa}$, the minimum is $109 \mathrm{kPa}$, the average is $156 \mathrm{kPa}$; the maximum vertical expansion of site No. 2 is $266 \mathrm{kPa}$ and the minimum is $64 \mathrm{kPa}, 160 \mathrm{kPa}$, with. Strong expansive soil compared to weak. The expansive soil expansive vertical expansive force dispersion results less, the proposed weak. In the expansive soil area vertical expansion force to take $160 \mathrm{kPa}$.

Take DKl68 +580.15 at a depth of $2 \mathrm{~m}$ of expansive soil carried a load expansion test showed that at $50 \mathrm{kPa}$ when the expansion rate of $1.77 \%, 100 \mathrm{kPa}$ when the expansion rate of $0.58 \%, 150$ $\mathrm{kPa}$ when the expansion rate of $0.20 \%$. Draw a plot of vertical expansive force versus expansion, as shown in Figure 3.

Similar to the analysis of medium-strong expansive soils, the relationship between vertical expansive force and expansiveness can be expressed as a linear equation $\mathrm{Y}=\mathrm{ax}+\mathrm{b}$, taking 5850.4, $\mathrm{b}=149.73$, and the correlation coefficient R2 $=0.9185$. Calculated weakly. In the expansive soil laboratory conditions, the vertical limit expansive force of $149.73 \mathrm{kPa}$. This value is close to the vertical limit expansive force obtained by the two in-situ tests, which verifies the rationality of the in-situ test results.

\section{Conclusion}

In this paper, the distribution and characteristics of expansive soil were investigated on site, to 
determine the medium - strong and weak - two sections of expansive soil test section. The expansive properties and strength characteristics of expansive soils in the experimental section were studied in situ. The characteristics of expansive force, swelling deformation and shear strength of undisturbed soils were obtained.

Through research - strong expansive soil and weak. The vertical expansive force of two kinds of soils was obtained in situ by vertical expansive force of expansive soil. The relationship between vertical expansive force and time, water content and unloading expansion was obtained. The conclusions are as follows:

(1) The maximum vertical expansive force of strong expansive soil is $338 \mathrm{kPa}$ and the minimum value is $100 \mathrm{kPa}$. Through statistical analysis, it is suggested. Strong expansive soil vertical limit expansive force take $200 \mathrm{kPa}$; weak. In the expansive soil vertical maximum limit expansive force of $266 \mathrm{kPa}$, the minimum value of $64 \mathrm{kPa}$, the recommended value of $160 \mathrm{kPa}$.

(2) The time-history characteristics of vertical expansive force obtained by in-situ tests of vertical expansive soil of middle-strong expansive soil and weak one middle expansive soil are similar. The growth of vertical expansive soil can be divided into three stages: rapid growth stage, stable growth stage, stable stage.

\section{Acknowledgement}

This work was financially supported by the Experimental Teaching Reform Fund of Huaqiao University (Nos. 66661507,66661625), the Natural Science Foundation of Fujian Province, China (2017J01095).

\section{References}

[1] Zhou B, Chen S, Yu F, et al. An in-situ testing method of swelling pressure on expansive soils[J]. Rock and Soil Mechanics, 2008, 29(12): 3333-3336.

[2] Miao L, Zhong X, YIN Z. Relationship between expansive soil strength and water content[J]. Rock and Soil Mechanics, 1996, 20(2): 71-75.

[3] Yang G L, Teng K, Qin C H. An in-situ experimental research of lateral swelling pressure on expansive soils[J]. Journal of Central South University (Science and Technology), 2014, 45(7): 2326-2332.

[4] DING J, CHEN R, TONG J, et al. Research on failure mechanism of shallow instability of expansive soil slope based on multifield coupling numerical analysis[J]. Rock and Soil Mechanics, 2015, 36(S1): 159-168.

[5] WANG N, ZHANG W, GU X, et al. Lateral swelling pressure of expansive soil acting on retaining wall due to inundation [J][J]. Journal of Hydraulic Engineering, 2008, 5.

[6] Yun X I E, Zheng-han C, Gang L I. Test research on three-dimensional swelling pressure of Nanyang expansive soil[J]. Journal of Logistical Engineering University, 2006, 22(1): 11-14.

[7] Chunlian W, Xinwan C. Effects of initial water content, dry unit weight and load on the swelling of clayey weak rock: an experimental study[J]. Chinese Journal of Rock Mechanics and Engineering, 1992, 11(3): 304-311.

[8] Qiang L U O, Ying C A I. SHAO Qi-hao. Experimental Study on Gravity Retaining Wall filled with Chengdu Clay[J]. Chinese Journal of Southwest Jiaotong University, 1995, 30(3): 270-274.

[9] An J, Jiang G, Wang Z. Analysis of shear strength of unsaturated expensive soil under plane strain test[J]. ROCK AND SOIL MECHANICS-WUHAN-, 2007, 28(12): 2649.

[10] YANG H, LIAO Y, ZHANG Z, et al. Experiment research on relationship between swelling force and allowable deformation[J]. 2010. 